\title{
Intelligent High-performance Dynamic Control for Two-stage Screw High-temperature Heat Pump System
}

\author{
Win-Jet Luo, ${ }^{*}$ Jin-Chang Lai, ${ }^{1}$ Po-Yuan Hsieh, ${ }^{2}$ and Fikri Rahmat Fasya ${ }^{2}$ \\ ${ }^{1}$ Graduate Institute of Precision Manufacturing Engineering, National Chin-Yi University of Technology, \\ No. 57, Sec. 2, Zhongshan Rd., Taichung 41170, Taiwan \\ ${ }^{2}$ Department of Refrigeration, Air Conditioning and Energy Engineering, \\ National Chin-Yi University of Technology, No. 57, Sec. 2, Zhongshan Rd., Taichung 41170, Taiwan
}

(Received March 28, 2018; accepted September 12, 2018)

Keywords: heat pump, flash tank, heat recovery, suitable vapor injection pressure, performance enhancement

In this study, we developed a new type of water-to-water two-stage screw heat pump with a vapor injection flash tank and investigated the performance of the heat pump under various condensation temperatures of the refrigeration cycle. In addition to the flash tank, a floodedtype evaporator and a shell-tube oil cooler for refrigeration oil heat recovery are implemented in the heat pump system. Suitable vapor injection pressures corresponding to different condensation temperatures were found. It was also found in this study, that with a suitable vapor injection pressure for operation, the average coefficient of heating performance can be enhanced by the investigated heat pump system under various condensation temperatures. An intelligent controlling strategy in terms of the subcooled degree was developed to attain the dynamic high performance of the heat pump under different condensation temperatures. From the performance measurements, it can be found that the average heating capacity improvement of $29 \%$ and the performance enhancement of $11 \%$ can be achieved by the two-stage water-towater heat pump by utilizing the controlling strategy to adjust the vapor injection and the oil heat recovery under different condensation temperatures.

\section{Introduction}

Nowadays, energy consumption and energy conservation problems have become global issues. Energy production and energy consumption as causes of global environmental problems have attracted the world's attention. In the 21st century, with the increasing popularity of sustainable energy development, the use of conventional energy, such as coal combustion, can directly affect the environment, such as air pollution and acid rain, and also enhance the greenhouse effect. Consequently, the requirements for improving air quality are growing in order to improve environmental health. For these reasons, the development of an efficient and clean energy technology has become the focus of attention.

*Corresponding author: e-mail: wjluo@ncut.edu.tw

https://doi.org/10.18494/SAM.2018.2070 
In terms of global energy consumption, building energy consumption accounts for about $40 \%$. Among them, the energy consumption for air conditioning and heating applications, domestic water heating, and industrial processes are larger than for any other aspects, such as lighting, transportation, or entertainment. With the rapid development of the economy and as the living standards of people continue to improve, the demands for thermal comfort by people in their own living environment are also increasing. Industrial power consumption accounts for $60 \%$ of the national power consumption in which high-temperature heat sources comprise the majority of the overall energy demand. In this context, studies on clean process technology and stable manufacturing environment to meet sustainable development are particularly urgent. ${ }^{(1)}$ The main domestic heating methods that are currently in use are fuel-sourced heating, electric heating, and heat pump heating.

The global annual fossil fuel consumption growth rate increased by $2.41 \%$ from $1990-2012$, and the global share of fossil fuel was $70.8 \%$ in $2012 .{ }^{(2)}$ This has effects related to global warming. Stern ${ }^{(3)}$ projected that economic loss due to global warming from 2007 to 2020 would be $13.8 \%$ of the global gross domestic product (GDP). Owing to these issues, demands for efficient energy consumption are increasing continuously. To meet these demands, each government is working hard on strengthening $\mathrm{CO}_{2}$ emission controls and the standards of product certification, and companies are spurring the development of new technology to achieve high energy efficiency. Also, the same demand is increasing for high efficiency in heating and cooling systems owing to an increase in customer recognition of energy conservation. The change from the existing fosssil-fuel system to a heat pump for heating and cooling is the result of these efforts.

The heat pump system has some disadvantages in terms of complex structures, the performance of the product and the change in building load have opposite trends. However, the demand for heat pump systems is increasing continuously because they possesses higher efficiencies than the existing heating system, and they can generate heat and cold simultaneously. Also, the utility of the heat pump stands out because of the development of technologies such as inverter technology, which is beneficial for responding effectively to the building load. ${ }^{(4)}$ Recent studies in the area of refrigeration cycles, with regard to the search for more efficient systems, have focused mainly on two specific areas: the development of new technologies using alternative cycles to attain better performance and the use of new refrigerants, pure or mixtures, aimed at environmental protection. Different alternative cycles have been studied, and there are many promising options to increase the thermodynamic efficiency in comparison with the conventional vapor compression cycle. Currently, some of the most explored alternative refrigeration cycles are ejector refrigeration, the cascade system, and the refrigerant injection system. ${ }^{(5)}$

Vapor injection technology has been applied in systems with a two-stage compressor in order to cool down the compressor and increase the subcooling of the refrigerant condensation. The refrigerant vapor-injection technique has been well demonstrated to improve the performance of systems in refrigeration applications. ${ }^{(6)}$ Cho et al. ${ }^{(7)}$ mentioned that the vapor injection technology can work effectively on both low- and high-ambient-temperature applications. Jiang et al. ${ }^{(8)}$ developed a general model for two-stage vapor compression heat pump systems. 
With a saturated injected refrigerant, the corresponding increments of coefficients of cooling performance (coefficient of performance; $C O P$ ) and heating performance $\left(C O P_{h}\right)$ are 23.4 and $15.4 \%$, respectively. The experimental studies conducted by Baek et al. ${ }^{(9)}$ revealed that the $C O P$ of the investigated two-stage $\mathrm{CO}_{2}$ heat pump is $7.6 \%$ higher than that without vapor injection, and the heating capacity is $13.7 \%$ higher than that without vapor injection under various condensation temperatures. The vapor injection technology applications to refrigeration systems and heat pump systems have attracted many scholars' attention over these past few years. Jin et al. ${ }^{(10)}$ designed and tested a two-stage heat pump with a flash tank. Experimental results showed that the system is capable of providing hot water of $50^{\circ} \mathrm{C}$ even when the outside temperature is $-20^{\circ} \mathrm{C}$, with a heating capacity of $4.71 \mathrm{~kW}$ and a $C O P$ of 1.76 , and the discharge temperature of the high-stage compressor is below $100{ }^{\circ} \mathrm{C}$.

In the two-stage heat pump with a flash tank, the liquid level in the flash tank is susceptible to refrigerant pressure variations during the frosting period. ${ }^{(11)}$ Thus, the control strategy of vapor injection has been a focus in recent studies. Xu et al. ${ }^{(12)}$ indicated the importance of controlling the flash tank vapor injection quantity in the performance of the heat pump. In their study, the refrigerant liquid level in the flash tank could be controlled effectively by adjusting the expansion valves at high- and low-pressure stages, and the injection valve in the auxiliary circuit of the refrigeration cycle, as well as the fluid window on the flash tank. The system could obtain the optimal refrigerant vapor injection quantity when the liquid level was controlled at $40-60 \%$ of the total height of the flash tank. Xu et al. ${ }^{(13)}$ developed a new type of cycle control strategy of the housing-type R-410a vapor injection flash tank heat pump system. The system uses an electronic expansion valve (EEV) and proportional-integral-derivative (PID) controller for expansion control at the high-pressure stage of a refrigeration cycle, and uses a thermostatic expansion valve (TXV) for expansion control at the low-pressure stage of the refrigeration cycle. The vapor superheat sensor is mounted at the vapor injection opening on the auxiliary circuits to detect the superheat of the refrigerant vapor injected into the compressor, so as to provide a control signal for EEV, so that the system can control the expansion valves of the high- and low-pressure stages in accordance with this signal for the internal liquid level control of the flash tank. Roh and $\mathrm{Kim}^{(14)}$ tested the two-stage compression cycle system with compressor operating frequencies of $60-100 \mathrm{~Hz}$. The test results showed that the intermediate pressure could increase the heating capacity of the condenser and the system efficiency effectively, but it limits the applicability of vapor injection. An appropriate vapor injection control strategy has a considerable effect on system performance and capability. Xu et al. ${ }^{(15)}$ indicated that the present studies of vapor injection techniques focus on the performance improvement provided by different system configurations, but the cycle control strategy of the flash tank has not been specified. Therefore, the authors proposed the vapor injection flash tank heat pump system using the R-410a refrigerant. The system control coordination used an EEV for high-level expansion and a TXV for low-level expansion, and a small electric heater was applied to the evaporator injection line to import the steam generated by overheating, so as to provide a control signal for the EEV. The system was tested in the transient and steady states. The experimental results showed the recommended superheat degree of 4-6 K for the refrigeration cycle by controlling the flash tank liquid level. Because the PID can provide accurate control of EEV, this control strategy is regarded as a reliable periodic control strategy. 
The vapor injection technology is usually applied to the two-stage compressor system to increase the heating capacity of a condenser and the system efficiency effectively. Redón et al. ${ }^{(16)}$ mentioned that the performance of an injection cycle will depend on 4 internal variables: pressure, the mass flow rate of the injected gas, the superheat of the injected gas, and the temperature of the refrigerant at the inlet of the expansion valve. Aligned with this research, Jiang et al. ${ }^{(17)}$ investigated the role of optimum intermediate pressure in the two-stage vapor compression heat pump design. They proved that with the increase in the heat exchanger subcooling parameter, more refrigerants are "injected" to improve the subcooling effect obtained by the interstage configuration. As a result, the intermediate pressure rises so that the high-stage compressor mass flow rate increases. For the same reason, the $C O P$ of the system is also enhanced. Furthermore, the use of the flash tank also has benefits and drawbacks. Flash tank systems allow heat pump systems to work close to the optimum condition, with greater capacities and lower discharge temperatures. Flash tank systems have the disadvantage of having constrained intermediate conditions, since the inlet of the expansion valve is saturated with liquid at an intermediate pressure and the inlet of the injection port is saturated with vapor at an intermediate pressure. Redón et al. ${ }^{(16)}$ analyzed the subcritical two-stage vapor injection heat pump systems with different working fluids (R-407c, R-22, R-290, and R-32) under different operating conditions. They found that these systems, compared with singlestage systems, show very significant improvement of the seasonal COP (more than $30 \%$ ) for applications of high temperature.

Nowadays, the vapor injection system is also implemented in the high-temperature heat pump cycle to enhance the system performance. He et al. ${ }^{(18)}$ conducted some studies to enhance the heating capacity of the high-temperature heat pump by installing the economizer vapor injector at the outlet of the condenser with the initial condensation temperature of $88{ }^{\circ} \mathrm{C}$. It was found that as the injection pressure increased from 0.82 to $0.98 \mathrm{MPa}$, the vapor injection flow ratio increased from 7.3 to $22.61 \%$ and the heating capacity increased by $7 \%$, but $C O P$ did not significantly increase. The economizer vapor injection technique could provide more than $16{ }^{\circ} \mathrm{C}$ of refrigerant subcooling at the EEV inlet for all the studied working conditions. This is essential for ensuring that the EEV can operate reliably in the high-temperature heat pump system. However, Lee et al. ${ }^{(19)}$ found that in a higher-compression-ratio application, the COP of the heat pump with vapor injection gradually decreased with increasing compression ratio.

Oquendo et al. ${ }^{(20)}$ compared the performances of a scroll compressor with vapor injection and a two-stage reciprocating compressor. It was found that the scroll compressor with vapor injection has better efficiency when working with pressure ratios below approximately 7.5. The scroll compressor with vapor injection also presents better volumetric efficiency than the twostage reciprocating compressor, and also, under moderate evaporation temperature conditions, the scroll compressor with vapor injection develops a higher cooling COP and capacity. Qiao et al. ${ }^{(21)}$ and Qi et al. ${ }^{(22)}$ investigated vapor injection technology in refrigeration systems.

Dione et al. ${ }^{(23)}$ studied the evaporation heat transfer of geothermal heat pumps. It was found that the heat transfer coefficient of the heat pump with R-134a as the refrigerant offers a better performance than the heat pumps that use azeotropic mixture compounds as working fluids. Jung et al. ${ }^{(24)}$ numerically investigated the effects of the injection-port design on the heating 
performance of an R134a heat pump with vapor injection in electric vehicles. It was found that greater improvements in the isentropic efficiency and $C O P$ can be attained as the injection-port angle increases. At an outdoor temperature of $-10{ }^{\circ} \mathrm{C}, C O P$ improvements for the singleand dual-injection ports against the noninjection heat pump are 7.5 and $9.8 \%$, whereas the isentropic efficiency improvements for the single- and dual-injection ports are 11.2 and $22.9 \%$, respectively.

In this study, the vapor injection technology was applied to a two-stage screw compressed water-source heat pump. The performance of the system was investigated under different operational condensation temperatures. The purpose of this study is to develop a two-stage water-to-water heat pump by using a flash tank in a high-temperature heat pump application and also, to determine the method of controlling the intermediate pressure to gain the best performance. The performance enhancement of the water-to-water two-stage heat pump upon installing the oil cooler is also one of the main focuses of this study.

\section{Experimental Methods}

\subsection{Principle of two-stage screw heat pump system}

Figure 1 shows the schematic piping diagram of the investigated two-stage refrigeration cycle in this study. In the implemented two-stage screw heat pump system with a flash tank in this study, the refrigerant passes through the compressor and is compressed. Then, the highpressure and high-temperature gas refrigerant from point 4 enters the oil separator where the oil is separated from the refrigerant and flows through a shell-and-tube oil cooler. After the oil temperature is decreased, it flows back into the compressor to avoid overheating of the operational compressor and to protect the compressor from damage or failure. After that, the

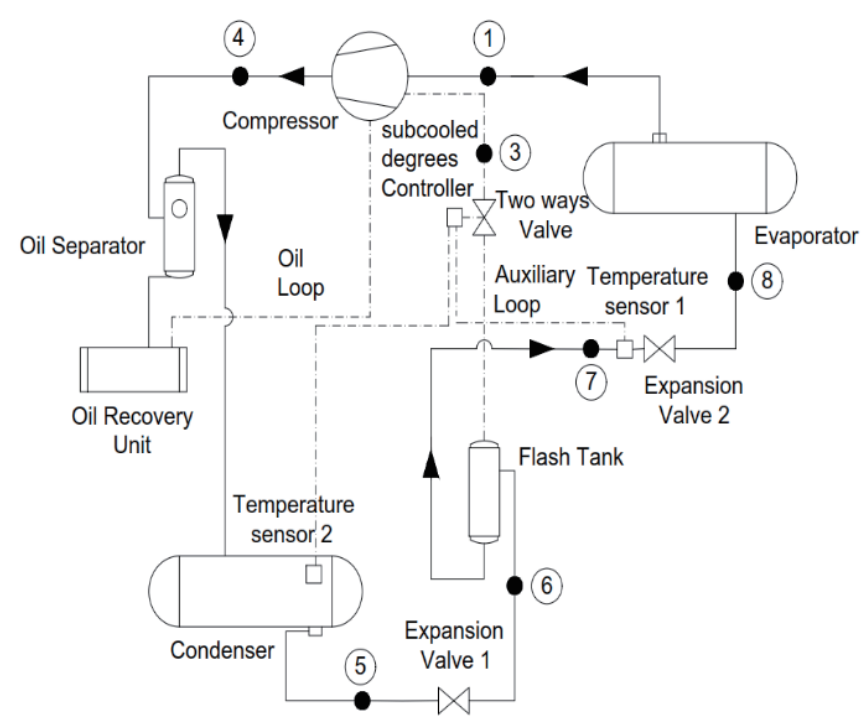

Fig. 1. Diagram of piping of two-stage screw heat pump system with flash tank. 
compressed refrigerant from the compressor enters the condenser. In this study, the water from the storage tank is also used to recover the wasted heat from the condenser, and the heated cooling water from the oil cooler flows to the condenser to absorb more heat and enhance the condenser capacity. After the condenser, the refrigerant enters expansion valve 1 at point 5 . The refrigerant at the outlet of expansion valve 1 (point 6) then enters the flash tank to increase the subcooled degree of the refrigerant, reducing the dryness of the refrigerant, so that the refrigerant is separated into the liquid refrigerant and gas refrigerant. In the flash tank, the refrigerant is divided into two loops: main loop and auxiliary loop. The main loop leads the liquid refrigerant through the inlet of expansion valve 2 (point 7), resulting in the formation of a low-pressure low-temperature refrigerant that enters the evaporator, where it absorbs heat from the environment. After that, the refrigerant flows to the suction line of the compressor at point 1 and it is compressed to the intermediate pressure by the lower-stage compressor. On the other loop, the vapor refrigerant from the flash tank is directly introduced to the intermediatepressure stage of the compressor at point 3 , where it is mixed with the compressed refrigerant from the suction line. Then, the mixed refrigerant is compressed in the compressor to a highpressure high-temperature vapor state and the cycle is repeated.

The main feature of the system investigated in this study is that the working pressure is divided into three states: low-pressure state, intermediate-pressure state, and high-pressure state. Compared with the regular water source heat pump unit, the system has some advantages such as reducing the compression ratio by dividing the compression into two stages, and higher performance and efficiency.

\subsection{Research method}

This study is based on a two-stage screw compressor heat pump system and the experiments were conducted at a Taiwan Accreditation Foundation (TAF)-certificated laboratory, in which the maximum measurement uncertainty should be within $5 \%$ in accordance with the national standard of certification. In the experiments associated with this study, the uncertainty of the experimental results, including flow rate, temperature, and power consumption, are also within $5 \%$. The system specifications are as follows.

1. High-temperature screw compressor: Type SRT321-HA; heating capacity, $350.75 \mathrm{~kW} ; 440 \mathrm{~V}$; $60 \mathrm{~Hz} ; 180.39 \mathrm{~A}$; maximum discharge temperature, $100{ }^{\circ} \mathrm{C}$; FUSHENG Industrial.

2. Shell and tube evaporator: capacity $246 \mathrm{~kW}$; overall heat transfer coefficient, $1580 \mathrm{~W} / \mathrm{m}^{2} \cdot \mathrm{K}$; approximate pressure drop, $70.0 \mathrm{kPa}$; length, $2.4 \mathrm{~m}$; Kuen Ling Machinery Refrigerating Co., Ltd.

3. Shell and tube condenser: capacity, $281 \mathrm{~kW}$; overall heat transfer coefficient, $4813 \mathrm{~W} / \mathrm{m}^{2} \cdot \mathrm{K}$; approximate pressure drop, $59.4 \mathrm{kPa}$; length, 2.4 m; Kuen Ling Machinery Refrigerating Co. Ltd.

4. Shell and tube oil cooler: $65 \mathrm{~L}$; length, $2687 \mathrm{~mm}$,

5. Oil separator: $120 \mathrm{~L}$; length, $1510 \mathrm{~mm}$; diameter, $500 \mathrm{~mm}$; Kuen Ling Machinery Refrigerating Co., Ltd.

In the experiments, the system was tested under three different conditions. First, the system 
was tested with and without vapor injection in order to understand the effect of the existence of vapor injection in the system performance. Secondly, the system was tested under different intermediate pressures in order to determine the suitable intermediate pressure, so that the system can be operated under optimal conditions. Finally, the system with oil heat recovery was tested and compared with that without oil heat recovery to evaluate the heating capacity improvement of the system. R-134a was selected as the refrigerant in the investigated twostage heat pump system. The evaporation temperature was maintained at $3{ }^{\circ} \mathrm{C}$. The thermal properties of R-134a at $3{ }^{\circ} \mathrm{C}$ are described in Table $1 .{ }^{(25)}$

In comparison with the reciprocating-type compressor, the screw-type compressor has a higher speed, lighter weight, smaller size, lower vibration, better dynamic balance, simpler structure, and fewer parts. Thus, it can have better energy optimization than the reciprocatingtype compressor. Rotary-screw-type compressors provide many advantages over their reciprocating-type compressor counterparts. Size, air delivery, duty cycle, and longevity are all factors that are firmly in favor of a screw compressor. ${ }^{(26)}$ With all of these advantages, the screw-type compressor has been widely used in recent years.

In comparison with the household-application heat pumps (condensation temperature: $50-60{ }^{\circ} \mathrm{C}$ ), the high-temperature heat pump has a higher condensation temperature. Most household-application heat pumps can generate hot water at temperatures of $40-50{ }^{\circ} \mathrm{C}$. However, for industrial application, the high-temperature heat pump can generate hot water at temperatures higher than $70{ }^{\circ} \mathrm{C}$. Recently, there have been two approaches that can be used in the high-temperature heat pump system, one is to use the $\mathrm{CO}_{2}$ refrigeration system and the other is to use the two-stage heat pump system. In this study, the two-stage heat pump system was investigated because the $\mathrm{CO}_{2}$ refrigeration system generates a very high condensation pressure. In this study, the high-temperature heat pump was developed especially for industrial application. Thus, the highest operational condensation temperature is 80 ${ }^{\circ} \mathrm{C}$, and the evaporation temperature is maintained at $3{ }^{\circ} \mathrm{C}$ for the heat pump system. The superheat degree was maintained at $3 \mathrm{~K}$ by attaching the sensing bulb of expansion valve 2 at the outlet of the evaporator. The liquid inside the bulb senses the superheat degree and then the liquid evaporates to control the opening of expansion valve 2. To understand the effect of condensation temperature on the system performance, the condensation temperature of the heat pump was varied so that the intermediate pressure can also be varied.

Table 1

Thermal properties of $\mathrm{R} 134 \mathrm{a}$ at $3{ }^{\circ} \mathrm{C}$.

\begin{tabular}{lcc}
\hline Parameter & Value & Unit \\
\hline Saturation pressure & 327.14 & $\mathrm{kPa}$ \\
Liquid density & 1285 & $\mathrm{~kg} / \mathrm{m}^{3}$ \\
Vapor density & 16.04 & $\mathrm{~kg} / \mathrm{m}^{3}$ \\
Enthalpy of vaporization & 196.4 & $\mathrm{~kJ} / \mathrm{kg}$ \\
Specific heat (liquid) & 1.352 & $\mathrm{~kJ} / \mathrm{kg} \cdot \mathrm{K}$ \\
Specific heat (vapor) & 0.9095 & $\mathrm{~kJ} / \mathrm{kg} \cdot \mathrm{K}$ \\
Dynamic viscosity (liquid) & $2.658 \times 10^{-4}$ & $\mathrm{~kg} / \mathrm{m} \cdot \mathrm{s}$ \\
Dynamic viscosity (vapor) & $7.947 \times 10^{-4}$ & $\mathrm{~kg} / \mathrm{m} \cdot \mathrm{s}$ \\
\hline
\end{tabular}


To improve the performance of the system, a two-stage compression system with intermediate pressure of vapor injection was adopted in this study. The theoretical model of the system is discussed in the following section. Figure 2 shows the thermodynamic states for the refrigeration cycle of the developed heat pump in terms of enthalpy (h, $\mathrm{kJ} / \mathrm{kg}$ ) and refrigerant absolute pressure (P, bar). From Fig. 2, it can be seen that $\dot{m}_{r}$ is the discharge flow rate of the refrigerant from the compressor (point 3 to point 4). After the discharge point of the compressor (point 4), the refrigerant flows through the condenser and enters expansion valve 1 at point 5 before entering the flash tank at point 6 . At expansion valve 1, the refrigerant's pressure is reduced and a mixture phase refrigerant is formed at the outlet of expansion valve 1. The refrigerant entering the flash tank is mostly liquid. In the flash tank, some refrigerant absorbs heat from the liquid refrigerant and evaporates into a fully saturated phase. By this heat exchange between the vapor and liquid refrigerant, the subcooling degree can be increased and the refrigerant can also be separated. It can be seen from Fig. 2 that refrigerant flow is divided into two loops after the flash tank. The main loop carries the refrigerant into expansion valve 2 at point 7 and then enters the evaporator at point 8 at the mass flow rate of $\dot{m}_{r l}$. After that, the refrigerant flows to the suction line of the compressor at point 1 at a low pressure and it is compressed by the first-stage compressor to an intermediate pressure. On the other loop, the vapor refrigerant from the flash tank is directly introduced to the compressor at point 3 with an intermediate pressure by the auxiliary loop. The refrigerant from the auxiliary loop (point 3) has a lower temperature than that from the first stage of the compressor, because the refrigerant is already compressed. Then the refrigerant from the auxiliary loop is mixed together with the refrigerant from the first-stage compressor in the intermediate stage of the compressor. The mixing effects cause the temperature of the discharge refrigerant from the first stage of the compressor to be reduced. After that, the refrigerant is compressed to a high-pressure hightemperature vapor state and the cycle is repeated.

If the cooling capacity is assumed to be $\Phi_{0}(\mathrm{~kJ} / \mathrm{s})$, the refrigerant mass flow rate through the low-pressure side, $\dot{m}_{r 1}(\mathrm{~kg} / \mathrm{s})$, is

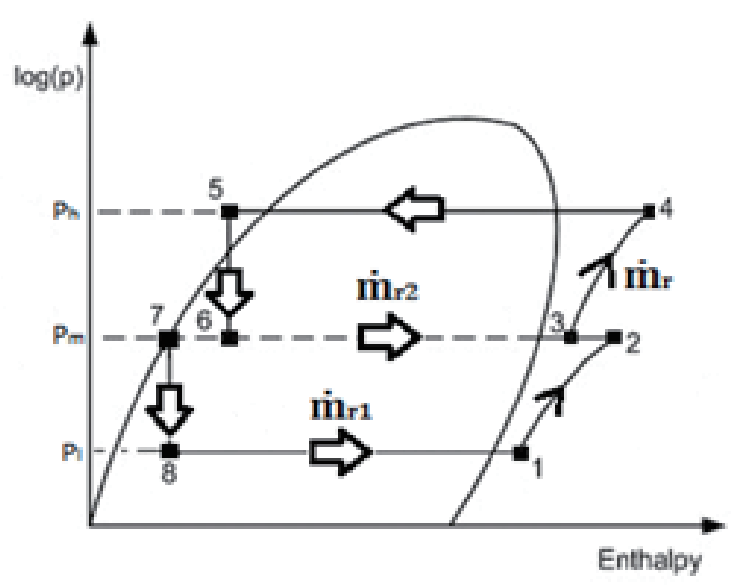

Fig. 2. Thermodynamic states for the refrigeration cycle of the developed heat pump. 


$$
\dot{m}_{r 1}=\Phi_{0} /\left(h_{1}-h_{8}\right)
$$

$\dot{m}_{r 1}$ is the refrigerant mass flow rate from the evaporator, and $h_{1}$ and $h_{8}$ are the enthalpy values at the outlet and inlet of the evaporator, respectively. The flow rate of the vapor injection refrigerant from the auxiliary loop, $\dot{m}_{r 2}(\mathrm{~kg} / \mathrm{s})$, can be found by using the following thermal equilibrium:

$$
\dot{m}_{r 2}=\left[\left(h_{2}-h_{3}\right)+\left(h_{5}-h_{7}\right)\right] m_{r 1} /\left(h_{3}-h_{4}\right),
$$

where $\dot{m}_{r 2}$ is the vapor injection refrigerant mass flow rate, $h_{2}$ is the enthalpy value of the refrigerant after achieving the lower compression, $h_{3}$ and $h_{6}$ are the enthalpy values of vapor injection at the outlet and inlet of the auxiliary loop, respectively, $h_{5}$ is the enthalpy value of the refrigerant at expansion valve 1 , and $h_{7}$ is the enthalpy value of the refrigerant at the flash tank. The total amount of refrigerant mass flow through the compressor discharge, $\dot{m}_{r}(\mathrm{~kg} / \mathrm{s})$, is

$$
\dot{m}_{r}=\left(h_{3}-h_{6}\right) \Phi_{0} /\left[\left(h_{3}-h_{6}\right)+\left(h_{1}-h_{8}\right)\right] .
$$

The power consumption of the low-pressure side of the compressor, $P_{t h 1}(\mathrm{~kW})$, is

$$
P_{t h 1}=\dot{m}_{r 1}\left(h_{2}-h_{1}\right)
$$

The power consumption of the high-pressure side of the compressor, $P_{t h 2}(\mathrm{~kW})$, is

$$
P_{t h 2}=\dot{m}_{r}\left(h_{4}-h_{3}\right)
$$

The instant cooling $C O P, C_{c}$, of the system is

$$
C O P_{c}=\dot{m}_{r 1}\left(h_{1}-h_{8}\right) /\left[\dot{m}_{r 1}\left(h_{2}-h_{1}\right)+\dot{m}_{r}\left(h_{4}-h_{3}\right)\right] .
$$

The instant coefficient of heating performance is

$$
C O P_{h}=\dot{m}_{r 1}\left(h_{4}-h_{5}\right) /\left[\dot{m}_{r 1}\left(h_{2}-h_{1}\right)+\dot{m}_{r}\left(h_{4}-h_{3}\right)\right] .
$$

Basically, the term $C O P$ refers to the ratio of desired benefits from a system divided by the total amount of work used to obtain the benefits. In this case, $C O P_{\text {total }}$ is defined as the total cooling and heating benefits from the heat pump system divided by the work of the compressor. Then, $C O P_{\text {total }}$ can be calculated as

$$
C O P_{\text {total }}=C O P_{c}+C O P_{h}
$$

The cooling/heating capacity of the heat pump is 


$$
Q=\dot{m} C p \Delta T
$$

where $Q$ is the cooling/heating capacity $(\mathrm{kW}), \dot{m}$ is the mass flow rate of the chilled/cooling water $(\mathrm{kg} / \mathrm{s}), C p$ is the specific heat $(\mathrm{kJ} / \mathrm{kg} \cdot \mathrm{K})$, and $\Delta T$ is the temperature difference of the chilled/cooling water in the evaporator/condenser $\left({ }^{\circ} \mathrm{C}\right)$. The geometrical mean of high and low pressures of the heat pump is used to estimate the suitable intermediate pressure. The geometrical mean pressure can be expressed as

$$
P_{m}=\sqrt{P_{h} P_{l}},
$$

where $P_{m}$ is the geometrical mean pressure (bar), $P_{h}$ is the high-pressure value (bar), and $P_{l}$ is the low-pressure value of the system (bar).

\section{Results and Discussions}

\subsection{Performance of two-stage heat pump with vapor injection}

The two-stage heat pump system was tested under an evaporation temperature of $3{ }^{\circ} \mathrm{C}$. When the intermediate pressure is maintained at $9.63 \mathrm{bar}$, the performance of the system is compared with that of the system without vapor injection in order to understand the effect of vapor injection on the performance of the heat pump system.

Table 2 lists the $C O P_{\text {total }}$ values of the system with and without vapor injection. As can be seen from Table 2, when the system is operated under a condensation temperature of $50{ }^{\circ} \mathrm{C}$ and the intermediate pressure is maintained at 9.63 bar, the system with vapor injection had a $C O P_{\text {total }}$ of 7.68 , which is $6 \%$ greater than that of the system operated without vapor injection with a $C O P_{\text {total }}$ of 7.20. At the condensation temperature of $85^{\circ} \mathrm{C}$ and intermediate pressure of 9.63 bar, the $C O P_{\text {total }}$ of the system with vapor injection is 3.61 . This value is $74 \%$ higher than that of the system without vapor injection. From those results, it can be determined that, regardless of the condensation temperature, the performance of the system can be improved effectively by introducing vapor injection into the compressor. From Table 2, it can be seen that with the

Table 2

$C O P_{\text {total }}$ with and without vapor injection.

\begin{tabular}{ccccccc}
\hline $\begin{array}{c}\text { Condensation } \\
\text { temperature } \\
\left({ }^{\circ} \mathrm{C}\right)\end{array}$ & $\begin{array}{c}C O P_{\text {total }} \\
\text { (without vapor } \\
\text { injection) }\end{array}$ & $\begin{array}{c}\text { COP total } \\
\text { (with vapor } \\
\text { injection) }\end{array}$ & $\begin{array}{c}\text { Increment } \\
\text { percentage }(\%)\end{array}$ & $\begin{array}{c}\text { Heating capacity } \\
\text { with vapor } \\
\text { injection }(\mathrm{kW})\end{array}$ & $\begin{array}{c}\text { Cooling capacity } \\
\text { with vapor } \\
\text { injection }(\mathrm{kW})\end{array}$ & $\begin{array}{c}\text { Compressor } \\
\text { work with vapor } \\
\text { injection }(\mathrm{kW})\end{array}$ \\
\hline 50 & 7.20 & 7.68 & 6.70 & 361.75 & 266.92 & 81.86 \\
55 & 6.38 & 6.79 & 6.40 & 342.91 & 215.21 & 86.62 \\
60 & 5.56 & 6.38 & 14.70 & 328.01 & 227.25 & 87.03 \\
65 & 4.97 & 5.58 & 12.27 & 317.94 & 195.86 & 92.08 \\
70 & 4.41 & 4.76 & 7.90 & 273.67 & 172.74 & 93.78 \\
75 & 3.74 & 4.23 & 13.10 & 251.58 & 165.25 & 98.54 \\
80 & 3.12 & 4.00 & 28.20 & 249.08 & 147.93 & 99.25 \\
85 & 2.07 & 3.61 & 74.40 & 246.57 & 130.61 & 104.48 \\
\hline
\end{tabular}


increase in condensation temperature, the $C O P_{\text {total }}$ of the system gradually decreases owing to the increase in the required compression work of the compressor.

Figure 3 shows $C O P_{\text {total }}$ of the system with vapor injection compared with that of the system without vapor injection under an intermediate pressure of 9.63 bar. From Fig. 3, it can be seen that the $C O P_{\text {total }}$ of the heat pump system can be considerably improved by vapor injection, and this improvement becomes apparent with increasing condensation temperature. By vapor injection, the compressor can be cooled and the compression efficiency of the compressor can also be improved. The subcooling degree and the cooling effect of the refrigeration cycle can be increased as well. In particular, when the compressor is operated under a high condensation temperature, the compression efficiency improvement by vapor injection is more apparent.

Table 3 shows $\mathrm{COP}_{h}$ values for the systems with and without vapor injection, and the simulation value in terms of condensation temperature rising under an intermediate pressure of $9.63 \mathrm{bar}$ and an evaporation temperature of $3{ }^{\circ} \mathrm{C}$. The simulation values are obtained using FUSHENG Refrigerant Compressor Selection Software. In the thermodynamic model, the pressure and heat losses in the high- and low-pressure sides are not considered. The refrigerant is assumed to be incompressible and the refrigeration cycle is assumed to be under the steady-

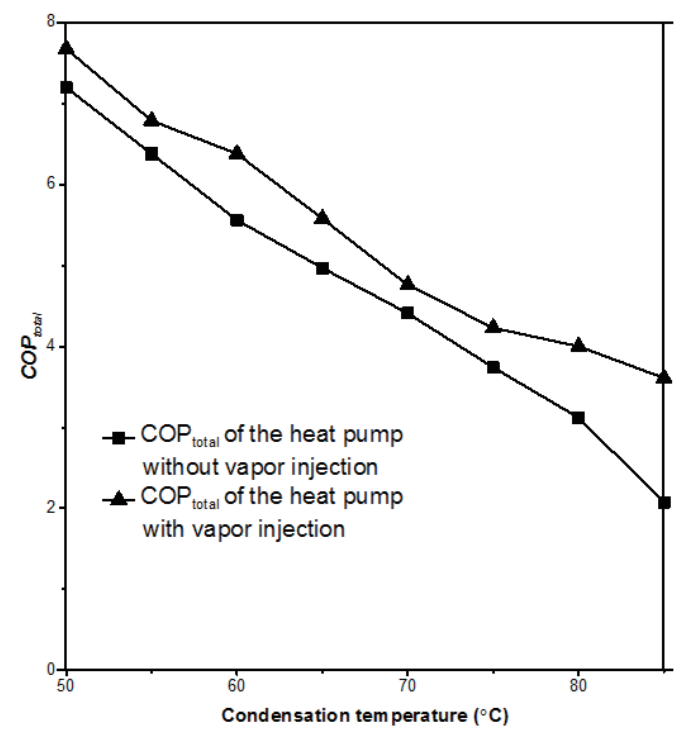

Fig. 3. COP total of heat pump with and without vapor injection.

Table 3

$C O P_{h}$ values of the heat pump and simulated values.

\begin{tabular}{cccc}
\hline $\begin{array}{c}\text { Condensation } \\
\text { temperature }\left({ }^{\circ} \mathrm{C}\right)\end{array}$ & $\begin{array}{c}\mathrm{COP}_{h} \text { (without } \\
\text { vapor injection) }\end{array}$ & $\begin{array}{c}\mathrm{COP}_{h} \text { (with } \\
\text { vapor injection) }\end{array}$ & $\begin{array}{c}\mathrm{COP} \\
\text { (simulation) }\end{array}$ \\
\hline 50 & 4.26 & 4.42 & 3.87 \\
55 & 3.89 & 4.28 & 3.61 \\
60 & 3.38 & 3.89 & 3.34 \\
65 & 3.28 & 3.50 & 3.14 \\
70 & 2.86 & 2.92 & 2.92 \\
75 & 2.44 & 2.55 & 2.74 \\
85 & 1.51 & 2.36 & 2.47 \\
\hline
\end{tabular}


state condition. In the experiments, the condenser has a higher heat exchanger efficiency, especially under low condensation temperatures. This is the reason why the simulated $C O P_{h}$ is smaller than $\mathrm{COP}_{h}$ determined experimentally at low condensation temperatures. From Table 3, it can be seen that when the condensation temperatures are 50 and $85{ }^{\circ} \mathrm{C}$, the $C O P_{h}$ values of the system without vapor injection are 4.26 and 1.51 , respectively. On the other hand, the corresponding values of the system with vapor injection are 4.42 and 2.36 , whereas the corresponding theoretical $\mathrm{COP}_{h}$ values are 3.87 and 2.47. It can be seen from Table 3 that when the system is operated under a condensation temperature of $50{ }^{\circ} \mathrm{C}$ with an intermediate pressure of 9.63 bar, the system with vapor injection exhibits a heating capacity improved by $3 \%$. In addition, this heating capacity is $14 \%$ higher than the theoretical value. However, when the system is operated under a condensation temperature of $85^{\circ} \mathrm{C}$, although the $C O P_{h}$ of the system with vapor injection is higher than that without vapor injection, it is lower than the simulation value. The reason for this result is that the optimum performance of the condenser can be obtained when the condensation temperature is $70^{\circ} \mathrm{C}$. Thus, after the condensation temperature reaches $70^{\circ} \mathrm{C}$, the performance of the condenser gradually degrades. However, the gap between the simulation values and the experimental results in this case is not very large. From the above discussions, it can be found that introducing an intermediate-pressure vapor refrigerant into the compressor can significantly improve the performance of the system.

\subsection{Suitable intermediate pressure of two-stage heat pump}

To determine the suitable intermediate pressure, the two-stage heat pump system was tested under different pressures. The result was then compared with the geometrical mean pressure. Figure 4 shows the two-stage heat pump system pressures and geometrical mean pressure. In addition, Table 4 shows the total performance and the corresponding pressures of the system under different condensation temperatures. From Tables 2 and 4, it can be found that at the condensation temperature of $60{ }^{\circ} \mathrm{C}$, the suitable intermediate pressure is 9.63 bar and $C O P_{\text {total }}$ is 6.38. When the condensation temperature is $65^{\circ} \mathrm{C}$, the suitable intermediate pressure is 11.35

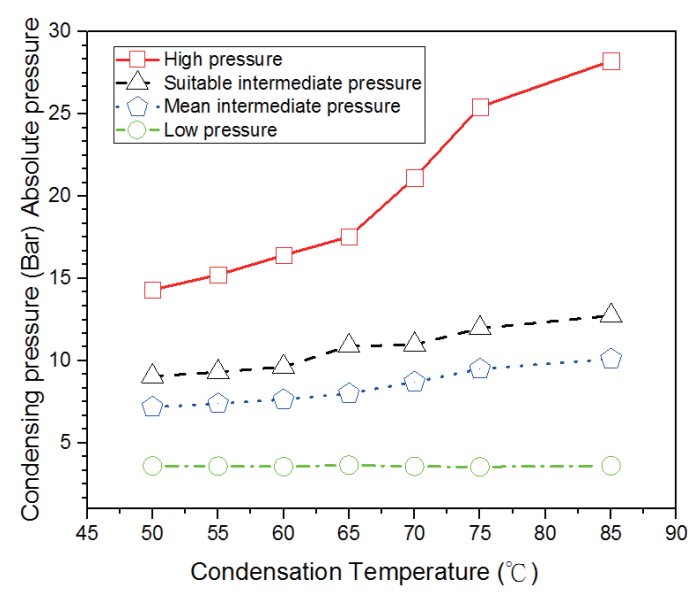

Fig. 4. (Color online) Pressure values of the system. 
Table 4

Pressure value and $C O P_{\text {total }}$ at suitable intermediate pressure of the system.

\begin{tabular}{cccccc}
\hline $\begin{array}{c}\text { Condensation } \\
\text { temperature }\left({ }^{\circ} \mathrm{C}\right)\end{array}$ & $\begin{array}{c}\text { Suitable intermediate } \\
\text { pressure (Bar) }\end{array}$ & $\begin{array}{c}\text { Mean intermediate } \\
\text { pressure (Bar) }\end{array}$ & $\begin{array}{c}\text { High pressure Low pressure } \\
\text { (Bar) }\end{array}$ & $\begin{array}{c}\text { COP } P_{\text {total }} \text { at suitable } \\
\text { intermediate } \\
\text { pressure }\end{array}$ \\
\hline 50 & 9.06 & 7.19 & 14.31 & 3.61 & 7.68 \\
55 & 9.31 & 7.39 & 15.22 & 3.59 & 6.79 \\
60 & 9.63 & 7.64 & 16.41 & 3.56 & 6.38 \\
65 & 10.9 & 8.01 & 17.54 & 3.66 & 4.76 \\
70 & 10.98 & 8.71 & 21.12 & 3.58 & 4.23 \\
75 & 11.97 & 9.50 & 25.43 & 3.55 & 4.00 \\
85 & 12.74 & 10.11 & 28.22 & 3.62 & 3.61 \\
\hline
\end{tabular}

bar and $C O P_{\text {total }}$ is 6.21 ; this value is $7 \%$ higher than that of the system when the intermediate pressure is 9.63 bar under the same condensation temperature of $65^{\circ} \mathrm{C}\left(C O P_{\text {total }}=5.78\right)$. When the condensation temperature is $85^{\circ} \mathrm{C}$, the suitable intermediate pressure is 11 bar with $C O P_{\text {total }}$ of 3.71. This value is $2 \%$ higher than that of the system under an intermediate pressure of 9.63 with $C O P_{\text {total }}$ of 3.61 under the same condensation temperature. In addition, it can be found from these results that the suitable intermediate pressure of the system can be set at about $26 \%$ higher than the geometrical mean pressure. This action can be implemented to gain the best system performance at different condensation temperatures and avoid energy waste of the system.

In this study, the evaporation temperature was maintained at $3{ }^{\circ} \mathrm{C}$. In addition, the condenser temperature was also set at certain values. To find the suitable intermediate pressure, some pressure conditions were tried until the intermediate pressure at which $C O P_{\text {total }}$ was higher than $C O P_{\text {total }}$ obtained at the geometrical mean pressure was found. From the results of the experiment, the suitable intermediate pressure was found to be approximately $26 \%$ higher than the geometrical mean pressure, and the corresponding subcooling degrees of the refrigeration cycle for different suitable intermediate pressures gradually rise with the increase in condensation temperature. Figure 5 illustrates the relationship between the condensation temperature and the corresponding subcooling degree of the refrigeration cycle.

When the condensation temperature is $50{ }^{\circ} \mathrm{C}$, the corresponding subcooling degree is $6.1{ }^{\circ} \mathrm{C}$. With the raise in the condensation temperature, the corresponding subcooling degree increases gradually. When the condensation temperature increases to $85^{\circ} \mathrm{C}$, the corresponding subcooling degree can reach $15.2^{\circ} \mathrm{C}$. A regression equation is obtained from the corresponding subcooling degrees by using least-squares approximation in order to further control the intermediate pressure of vapor injection to attain a high heating performance of the system. The regression equation for the relationship between subcooling degree $\left(T_{s c}\right)$ and condensation temperature $\left(T_{c}\right)$ is $T_{s c}=18.91922+-0.53926^{*} T_{c}+0.0058^{*} T_{c}^{2}$ with $R^{2}=0.97847$.

\subsection{Heat recovery effect of oil cooler}

In the previous section, the suitable intermediate pressure of a two-stage refrigeration cycle in the high-temperature heat pump system was discussed. In this section, we will discuss the 


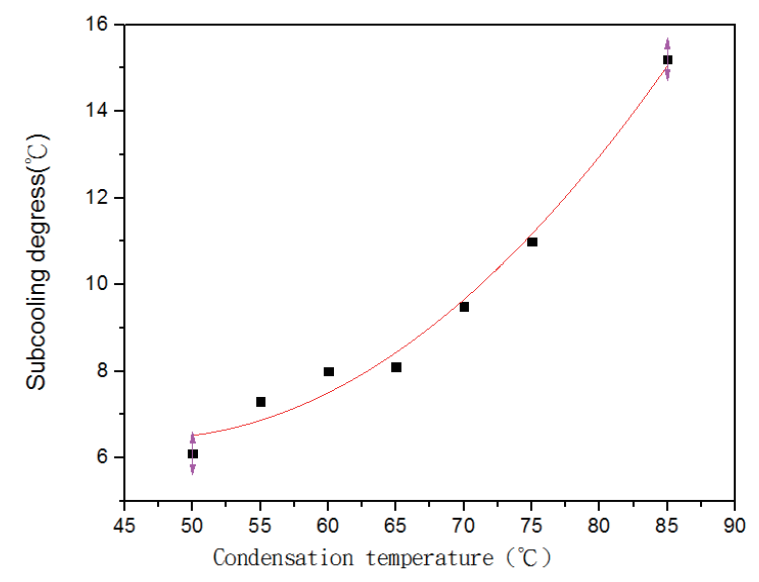

Fig. 5. (Color online) Relationship between condensation temperature and the corresponding subcooling degree.

operation of the oil cooler for heat recovery. The cooling water flow rate is fixed at an average of 395.5 liters per minute $(\mathrm{lpm})$ and the cooling water inlet temperature is varied under different condensation temperatures. The cooling water is used to cool the oil, and then it is introduced into a preheated water tank. The water temperature within the condenser is maintained at high temperatures, so that the required heating capacity of the condenser is reduced and the performance of the system is improved owing to the preheating of the water supplied to the condenser using the heat recovered from the oil cooler. The water inlet and outlet temperatures of the oil cooler are shown in Table 5.

Table 6 shows the system capacity before and after adding the heat recovery under different condensation temperatures, and the results are plotted in Fig. 6. From Table 6, the oil heat recovery is seen to be considerable, especially at high condensation temperatures, although at low condensation temperatures, it is still quite good. Thus, oil cooler heat recovery can further enhance the system performance to achieve the purpose of energy optimization.

Table 7 shows the system performance $\left(C O P_{\text {total }}\right)$ of the system before and after adding oil heat recovery under different condensation temperatures. In the system with oil heat recovery, the cooling water is circulated by an additional pump. The work needed by the pump to circulate the water is not considered in the COP calculation. In other words, the $C O P$ calculation only considers the work of the compressor. In the system without oil heat recovery, the oil from the oil separator directly enters the compressor by the suction effect of the compressor. This kind of design without the oil heat recovery is common in most applications. In this kind of design, the oil enters the compressor at a high temperature. Therefore, there is some heat that can be recovered from the oil to be used for other purposes. Therefore, in this study, the authors proposed the oil heat recovery design in order to maximize heat utilization. As shown in Table 7, the addition of oil cooler heat recovery at the condensation temperature of $50{ }^{\circ} \mathrm{C}$ can improve the system performance by $17 \%$. When the condensation temperature is 85 ${ }^{\circ} \mathrm{C}$, the performance of the system increases by $35 \%$. At the condensation temperature of $70{ }^{\circ} \mathrm{C}$, the performance improvement is about $28 \%$. The average performance enhancement due to oil cooler heat recovery is $29 \%$. 
Table 5

Inlet and outlet water temperatures of oil cooler.

\begin{tabular}{ccc}
\hline $\begin{array}{c}\text { Condensation } \\
\text { temperature }\left({ }^{\circ} \mathrm{C}\right)\end{array}$ & $\begin{array}{c}\text { Water inlet } \\
\text { temperature }\left({ }^{\circ} \mathrm{C}\right)\end{array}$ & $\begin{array}{c}\text { Water outlet } \\
\text { temperature }\left({ }^{\circ} \mathrm{C}\right)\end{array}$ \\
\hline 45 & 2.01 & 23.9 \\
50 & 2.07 & 24.6 \\
55 & 21.1 & 25.2 \\
60 & 21.4 & 25.7 \\
65 & 21.9 & 26.3 \\
70 & 22.4 & 27.0 \\
75 & 22.9 & 27.6 \\
85 & 24.5 & 29.4 \\
\hline
\end{tabular}

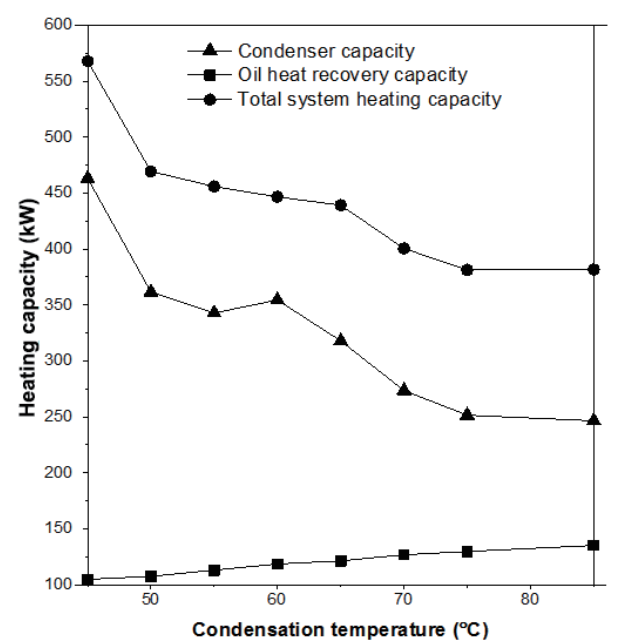

Fig. 6. Capacity before and after adding heat recovery.

Table 6

System capacity before and after adding heat recovery.

\begin{tabular}{cccc}
\hline $\begin{array}{c}\text { Condensation } \\
\text { temperature }\left({ }^{\circ} \mathrm{C}\right)\end{array}$ & $\begin{array}{c}\text { Condenser } \\
\text { capacity }(\mathrm{kW})\end{array}$ & $\begin{array}{c}\text { Oil heat recovery } \\
\text { capacity }(\mathrm{kW})\end{array}$ & $\begin{array}{c}\text { Total capacity } \\
(\mathrm{kW})\end{array}$ \\
\hline 45 & 463.11 & 104.9 & 568.0 \\
50 & 361.75 & 107.6 & 469.4 \\
55 & 342.91 & 113.1 & 456.0 \\
60 & 354.61 & 118.6 & 446.7 \\
65 & 317.94 & 121.4 & 439.3 \\
70 & 273.67 & 126.9 & 400.6 \\
75 & 251.58 & 129.7 & 381.3 \\
85 & 246.57 & 135.2 & 381.8 \\
\hline
\end{tabular}

Table 7

$C O P_{\text {total }}$ before and after adding oil heat recovery.

\begin{tabular}{cccc}
\hline $\begin{array}{c}\text { Condensation } \\
\text { temperature }\left({ }^{\circ} \mathrm{C}\right)\end{array}$ & $\begin{array}{c}C O P_{\text {total }} \text { (without } \\
\text { heat recovery) }\end{array}$ & $\begin{array}{c}C O P_{\text {total }} \text { (with heat } \\
\text { recovery) }\end{array}$ & $\begin{array}{c}\text { Increment } \\
\text { percentage (\%) }\end{array}$ \\
\hline 50 & 7.68 & 9.00 & 17.00 \\
55 & 6.79 & 8.40 & 20.00 \\
60 & 6.38 & 7.40 & 21.00 \\
65 & 5.80 & 7.10 & 23.00 \\
70 & 4.76 & 6.10 & 28.00 \\
75 & 4.23 & 5.60 & 31.00 \\
80 & 4.00 & 6.10 & 28.00 \\
85 & 3.61 & 4.90 & 35.00 \\
\hline
\end{tabular}

From the above discussion, it can be concluded that oil heat recovery can effectively improve the total heating capacity and the overall system performance at different condensation temperatures. The average performance enhancement of $29 \%$ can be achieved by incorporating oil cooler heat recovery at different condensation temperatures. Thus, oil heat recovery is very important in improving the performance of the system. 


\section{Conclusions}

From the above results and discussion, it was proven that a system with vapor injection is better than that without vapor injection in terms of efficiency and performance. In this study, the intermediate pressure could be controlled in terms of the subcooled degree under different condensation temperatures, in order to determine the best condition for the system to function under optimal conditions. In addition, in this study, we recovered the waste heat of the oil cooler, which was wasted in the prototype system. The heated water from the oil cooler was stored in a storage tank and used as water-tank-recovered heat from the condenser. The heat exchange capacity of the condenser was increased, improving the heating performance of the system. The experimental results showed that the oil cooler heat recovery can effectively improve the system heating capacity, so that the system can generate more heat in pursuit of energy optimization.

\section{Acknowledgments}

The authors gratefully acknowledge the financial support provided to this study by the Ministry of Science and Technology of Taiwan under Grant No. MOST 106-2622-E-167-006CC3.

\section{References}

1 K. Li, W. J. Luo, J. Z. Huang, Y. C. Chan, Pratikto, and D. Faridah: Appl. Sci. 7 (2017) 420.

2 J. Asafu-Adjaye, D. Byrne, and M. Alvarez: Energy Econ. 60 (2016) 345.

3 N. Stern: The Economics of Climate Change: The Stern Review (Cambridge University Press, Cambridge, United Kingdom, 2007).

4 C. W. Roh and M. S. Kim: Int. J. Refrig. 35 (2012) 434.

5 J. V. H. D’Angelo, V. Aute, and R. Radermacher: Int. J. Refrig. 65 (2016) 194.

6 X. Wang, J. Yu, and M. Xing: Energy Convers. Manage. 100 (2015) 242.

7 I. Y. Cho, H. J. Seo, D. Kim, and Y. Kim: Energy 112 (2016) 179.

8 S. Jiang, S. Wang, X. Jin, and T. Zhang: Int. J. Refrig. 51 (2015) 88.

9 C. Baek, J. Heo, J. Jung, H. Cho, and Y. Kim: Energy 77 (2014) 570.

10 X. Jin, S. Wang, and M. Huo: First Int. Conf. Building Energy and Environment (COBEE) (2008) 1437.

11 H. Qiao, V. Aute, and R. Radermacher: Int. J. Refrig. 84 (2017) 181.

12 X. Xu, Y. Hwang, and R. Radermacher: Int. Refrigeration and Air Conditioning Conf. (2010) 1.

13 X. Xu, Y. Hwang, and R. Radermacher: Int. J. Refrig. 34 (2011) 402.

14 C. W. Roh and M. S. Kim: Int. J. Refrig. 34 (2011) 1911.

15 X. Xu, Y. Hwang, and R. Radermacher: Int. J. Refrig. 34 (2011) 1922.

16 A. Redón, E. Navarro-Peris, M. Pitarch, J. Gonzálvez-Macia, and J. M. Corberán: Appl. Energy 124 (2014) 231.

17 S. Jiang, S. Wang, X. Jin, and Y. Yu: Int. J. Refrig. 70 (2016) 57.

18 Y. He, F. Cao, L. Jin, X. Wang, and Z. Xing: Int. J. Refrig. 60 (2015) 1.

19 D. Lee, K. J. Seong, and J. Lee: Int. J. Refrig. 53 (2015) 115.

20 F. M. T. Oquendo, E. Navarro-Peris, J. Gonzálvez-Macia, and J. M. Corberán: Int. J. Refrig. 63 (2016) 144.

21 H. Qiao, V. Aute, and R. Radermacher: Int. J. Refrig. 84 (2017) 181.

22 H. Qi, F. Liu, and J. Yu: Int. J. Refrig. 74 (2017) 540.

23 Kh. R. Dione, H. Louahlia, M. Mario, and J. L. Bercaits: Int. Commun. Heat Mass. 93 (2018) 1.

24 J. Jung, Y. Jeon, H. Lee, and Y. Kim: Appl. Therm. Eng. 127 (2017) 800.

25 F. P Incropera and D. P. DeWitt: Fundamentals of Heat and Mass Transfer (John Wiley \& Sons Inc., New Jersey, USA, 1990) 3rd ed.

26 VMAC Air Innovated, Rotary Screw VS Reciprocating Air Compressors: Performance Differences. Available online: https://www.vmacair.com/blog/rotary-screw-vs-reciprocating-air-compressors-performancedifferences/ (accessed March 2018). 